\title{
Erratum to: Comparative chloroplast DNA phylogeography of two tropical pioneer trees, Macaranga gigantea and Macaranga pearsonii (Euphorbiaceae)
}

Daniela Guicking • Brigitte Fiala • Frank R. Blattner • Ferry Slik • Maryati Mohamed • Kurt Weising

Published online: 30 July 2011

(C) Springer-Verlag 2011

Erratum to: Tree Genetics \& Genomes (2011) 7:573-585

DOI 10.1007/s11295-010-0357-z

Due to a technical error wrong versions of Figures $2 \mathrm{a}$ and $\mathrm{b}$ have been published

Please find the correct Figures $2 \mathrm{a}$ and $\mathrm{b}$ below.

Communicated by Y. Tsumura

The online version of the original article can be found at at http://dx. doi.org/10.1007/s11295-010-0357-z.

D. Guicking $(\bowtie) \cdot K$. Weising

Systematics and Morphology of Plants, University of Kassel, 34132 Kassel, Germany

e-mail: guicking@uni-kassel.de

B. Fiala

Department of Animal Ecology and Tropical Biology,

University of Würzburg,

97074 Würzburg, Germany

F. R. Blattner

Leibniz Institute of Plant Genetics and Crop Research (IPK), 06466 Gatersleben, Germany

F. Slik

Key Laboratory in Tropical Forest Ecology, Xishuangbanna,

Tropical Botanical Garden, Chinese Academy of Sciences,

Menglun,

Mengla, Yunnan, China

M. Mohamed

Institute for Tropical Biology and Conservation (ITBC),

University Malaysia Sabah,

88999 Kota Kinabalu, Malaysia 

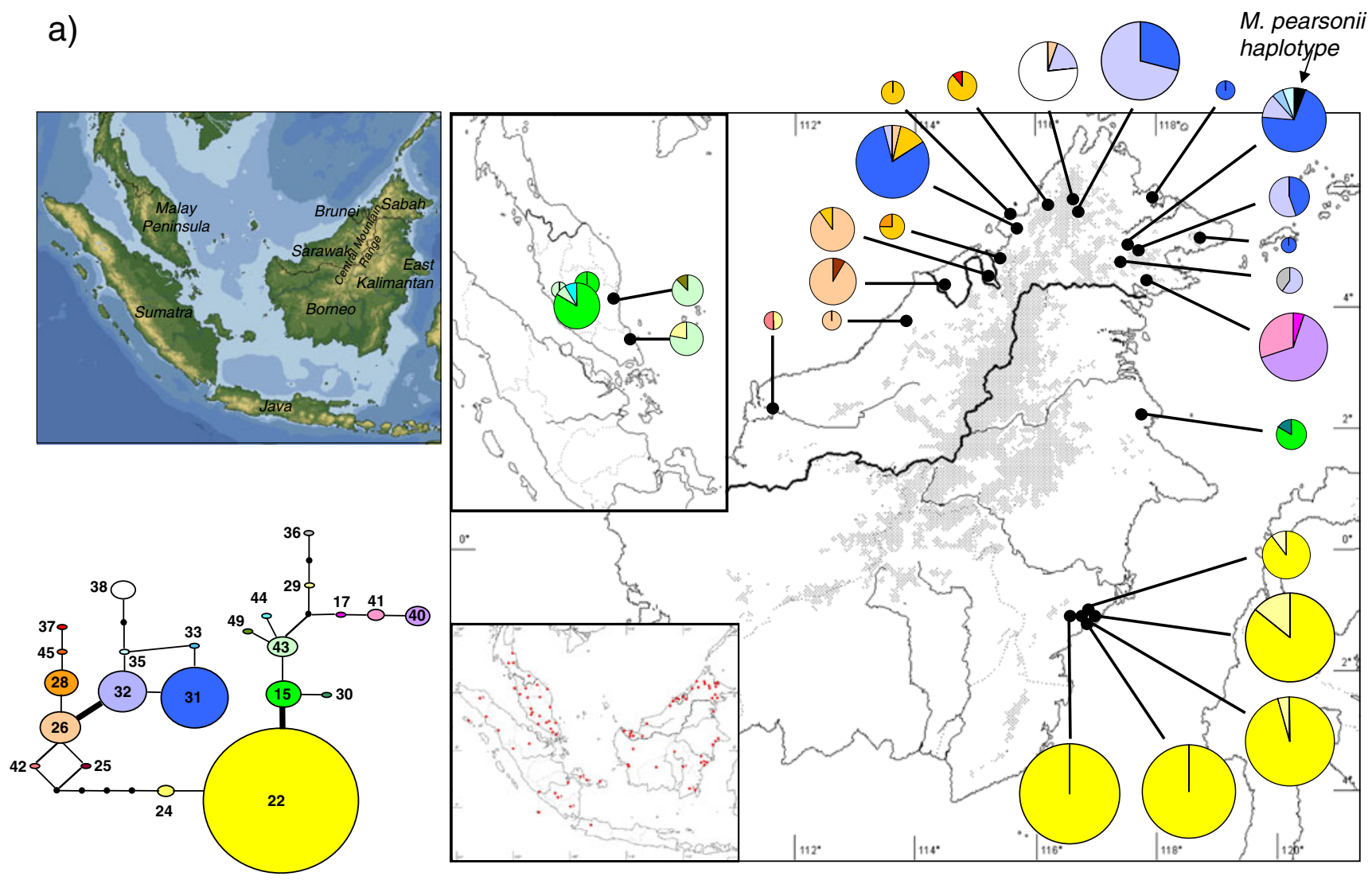

b)
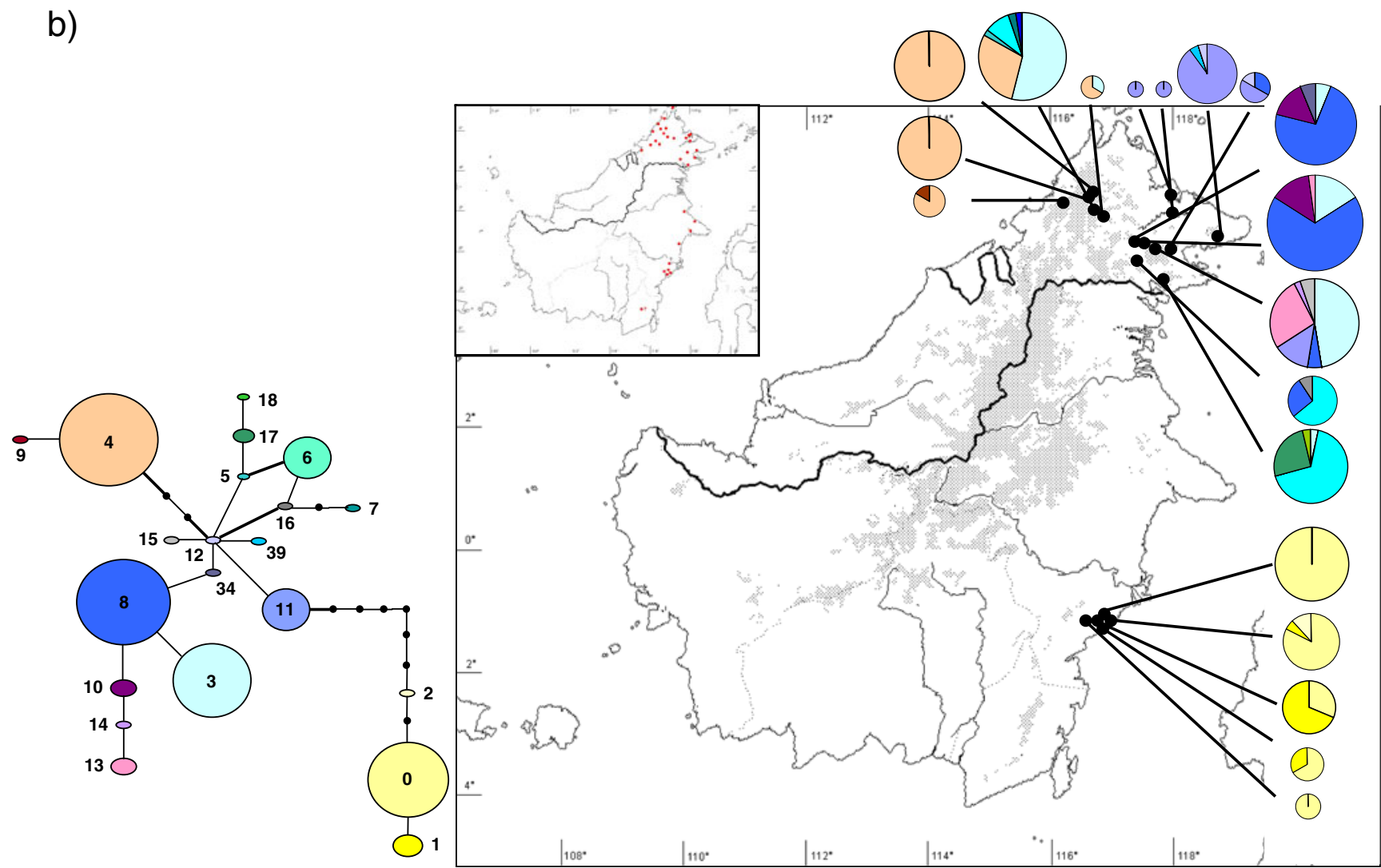